\title{
Reconciling Micro- and Macroeconomics: The Interaction of Innovations, Imitations and Personal Income Distribution
}

\author{
Friedrich L. Sell \\ Bundeswehr University, Munich, Germany \\ Email: friedrich.sell@unibw.de
}

How to cite this paper: Sell, F. L. (2020). Reconciling Micro- and Macroeconomics: The Interaction of Innovations, Imitations and Personal Income Distribution. Modern Economy, 11, 1012-1025.

https://doi.org/10.4236/me.2020.115076

Received: February 28, 2020

Accepted: May 6, 2020

Published: May 9, 2020

Copyright $\odot 2020$ by author(s) and Scientific Research Publishing Inc. This work is licensed under the Creative Commons Attribution International License (CC BY 4.0).

http://creativecommons.org/licenses/by/4.0/ Open Access

\begin{abstract}
The paper is a successor of original papers presented previously by Blümle (1989) and Sell (2020). Drawing on insights provided already by Enrico Barone in the 1930's, we establish a relationship between the distribution of personal incomes and the activities of innovation and imitation. The model we set up may be taken both as a microeconomic and/or a macroeconomic contribution. On the micro level, champion firms like Google, Amazon, Microsoft or Facebook generate fabulous innovations which are accompanied by large profits and, at the same time, an intra-firm concentration of wages and salaries (including bonuses). On the macro level, the upper (lower) swing of the business cycle goes hand in hand with a rising (falling) profit quota/a higher (lower) inter-firm slope of earnings, created to a large extent by innovative Schumpeterian monopolists (imitative entrepreneurs). Finally, we want to find some empirical evidence for our theoretical results. The work concludes with a summary of our exposition along with some thoughts about policy implications.
\end{abstract}

\section{Keywords}

Innovation, Imitation, Personal Income Distribution, Modeling of the Business Cycle Based on Microeconomic Foundation

\section{Introduction}

The structure/dynamics of (absolutely and relatively rising) profits vis-vis to (at least relatively falling) wages and salaries we can observe inside highly innovative champion firms like Amazon, Facebook, Microsoft, Apple, etc. provides us with a twofold cognitive effect: it is able not only to explain the deterioration of the wage quota in the recent past (Autor, Dorn, Katz, Patterson, \& Van Reenen, 
2020) but also to shed light on the increasing concentration in personal income distribution. The deterioration of the wage quota, as well as the increasing concentration in personal income distribution, can be registered both on the firm as well as on the macroeconomic level. One simple explanation for this duplicity refers one to a simple structure effect: if the alleged processes take place on the firm level, these will be translated more so into the macroeconomy, the higher the contribution of these firms to total production is, measured for example as a share of GDP. It is a matter of fact that this share has been rising over (at least) the last ten to fifteen years. So far, so good.

If the above-mentioned firms can consolidate a permanent monopolistic position on their relevant market, one cannot expect the profit quota to come down again and the concentration of personal incomes to relent. This may happen. According to Schumpeterian economics, one may as well expect something different. The erosion of extraordinary monopolistic profits is due to the activities of imitating companies. These firms are primarily successful during the economic downswing of the cycle, a phase during which the profit quota tends to decline. Notice that the mapping between innovation/imitation and specific firms is not forever: Remember the case of the earlier Finnish champion "Nokia": being successfully innovative for a long time, it went almost bankrupt when it was unable to listen to the winds of change on the market for smartphones. And it became a tolerable imitator .... Notice also that, according to new insights, it appears doubtful whether the usage of the internet does contribute too much to creativity and hence to innovations: the so-called Matthew-effect explains that a research conducted by Google, for example, will tend to replicate already well-known results (Karabasz, 2020).

The paper is organized as follows: in the next (second) section, the basic content of the Schumpeterian competition theory is presented, which can be best explained using the example of the Barone curve. Thereafter, in the third section, we put forward key aspects of income distribution related to the cycle of innovations and imitations. The latter is modeled in the fourth section. Macroeconomic extensions to the business cycle will be presented in the fifth section. The sixth section looks for some empirical evidence. We conclude in the seventh section.

\section{The Original Barone Curve}

Enrico Barone was an economist stemming from Italy, born in 1851 and died in 1924. Professionally, he started as an officer in the army and later became a professor of economics. He is known for several achievements (Bradley \& Mosca, 2012). One of them is his monography on "economic accounting in a centrally directed economy without private ownership", another is the development of a curve named after him the Barone curve (Barone, 1935). In the Barone curve (Figure 1), all firms are ranked from left to right according to the minimum of their unit costs of production and an upward stepping curve is achieved when all capacities of production are ordered in a line with their respective unit costs. 


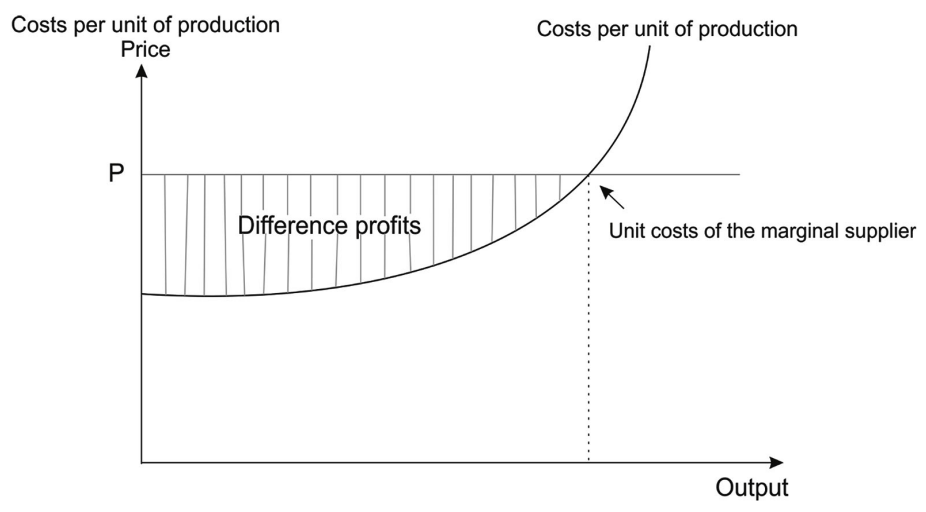

Figure 1. The original Barone-Curve. Sources: Blümle (1989) and Külp (2017).

It holds for each firm that its marginal costs curve intersects the respective unit cost curve at its respective minimum. The individual supply is then explained by the intersection between one's marginal costs with the horizontal price line. Aggregating all individual marginal cost curves yields the total supply curve. Then, it is the intersection of this supply curve with the price line that explains the amount of market production (Helmstädter, 1986).

Suppose initially, for a given price of height $\mathrm{P}$, the intersection of the Barone curve with this price level determines the actual size of the output. The intersection point on the Barone curve is necessarily associated with a point on the aggregate marginal cost curve. Thus, exactly, it is the point where a "marginal supplier" may cover his unit costs by his revenue per unit of production, given by the price. His net earnings per unit of production are hence zero. This also implies that all former (i.e., more efficient) suppliers on the market can earn positive profits per unit of production. In Figure 1, this fact is illustrated by the (vertical hatched) area below the price line, to the right of the ordinate and above the Barone curve (the aggregate unit costs of production curve). This area is called the "total economy difference profit".

The area below the Barone curve can be interpreted as the sum of all factor costs. What might be the possible reasons for the existence of different unit costs of production? Barone himself pointed out the different capacities for innovation distributed among the firms. The entrepreneurs, who are capable to introduce innovations into their technology of production, will reap benefits and hence be able to produce at lower costs than their competitors. Consequently, there will appear a slope among the profits of the suppliers. An innovation, hence, will always tend to lower the unit cost of production and increase accordingly the level of profit per unit of production. The suppliers, who reveal cost advantages due to the effects of innovation, will, therefore, achieve different profits. A special case can be given as when all firms exhibit identical cost structures or employ identical technologies of production. In this and only in this case, the unit costs of the product will be identical for all firms and the Barone curve will appear a horizontal line, perfectly parallel to the abscissa. In extremis, 
all firms exhibit cost coverage so that the Barone curve will appear geometrically identical with the horizontal price line in Figure 1.

Helmstädter (1986) interpreted this diagram concerning circular, total economic effects. In a closed economy without government, the total unit costs of production may as well be taken as labor unit costs. The area below the Barone curve then equals the total wage sum (which also stands for the total private consumption when workers do not save) and the area of difference profits represents total investment and savings in the economy under the supposition that profit earners do not consume.

\section{Distributional Aspects of the Barone-Curve}

The slope of profits, as explained earlier, can be described by a left-steep or skewed section to the right distribution of profits per unit of production (Blümle, 1989). The same pattern is represented by a lognormal distribution of profits (see Figure 2).

The underlying log-normal distribution is characterized by the following parameters: the variance of the $\log$ of profits per unit of production (labeled $V$ $v=\sigma^{2}$ ) and the arithmetic mean of the log of profits per unit of production $\left(\mu=\frac{1}{n} \sum \ln g\right.$ ). It should be pointed out that in such a scenario, modus, arithmetic mean, and median share the same position on the $\mathrm{x}$-axis (see Figure 2).

As is well known, the median of a frequency distribution indicates the expression of a single occurrence with the highest density. The median, in turn, symbolizes an event, which separates the frequency distribution into two halves. The symmetrical distribution of the log of profits per unit of production matches a left steep distribution of the original values of the profits per unit of production. Making such an assumption seems to be more realistic in the case of innovators because they are capable of achieving higher profits per unit of production than their (many) imitators.

Let's do the following experiment (see Figure 3): if we increase the standard deviation, say by substituting distribution of type I by that of type II, the following results will emerge. The modus will shift (from $\operatorname{Mod}_{1}$ to $\operatorname{Mod}_{2}$ ) to the left, the arithmetic mean will shift (from $\mathrm{ga}_{1}$ to $\mathrm{ga}_{2}$ ) to the right, while the position of the median $\left(\mathrm{Med}_{1}=\mathrm{Med}_{2}\right)$ will remain unchanged (see Figure 3$)$. These findings will be explored below in more detail by considering three propositions.

Departing from the assumption of a log-normal distribution of profits per unit of production $(g)$, the expected or likewise average profit rate $\left(g_{a}\right)$ per unit of production is then given by the following expression (see Beichelt \& Montgomery, 2003: pp. 46-48):

$$
E(g)=g_{a}=\exp \left(\mu+\frac{1}{2} \sigma^{2}\right)
$$

Taking the full differentiation of this expression from the left to right leads to:

$$
\mathrm{d} E(g)=\mathrm{d} g_{a}=(\mathrm{d} \mu+\sigma \mathrm{d} \sigma) \exp \left(\mu+\frac{1}{2} \sigma^{2}\right)
$$




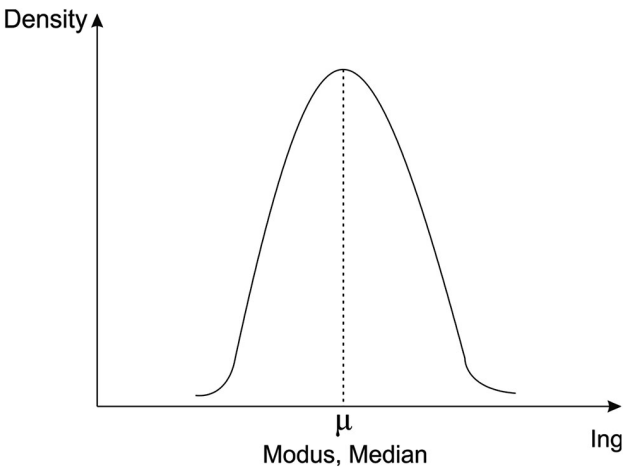

Figure 2. Symmetrical distribution of the log of profits per unit of production. Source: Blümle (1989).

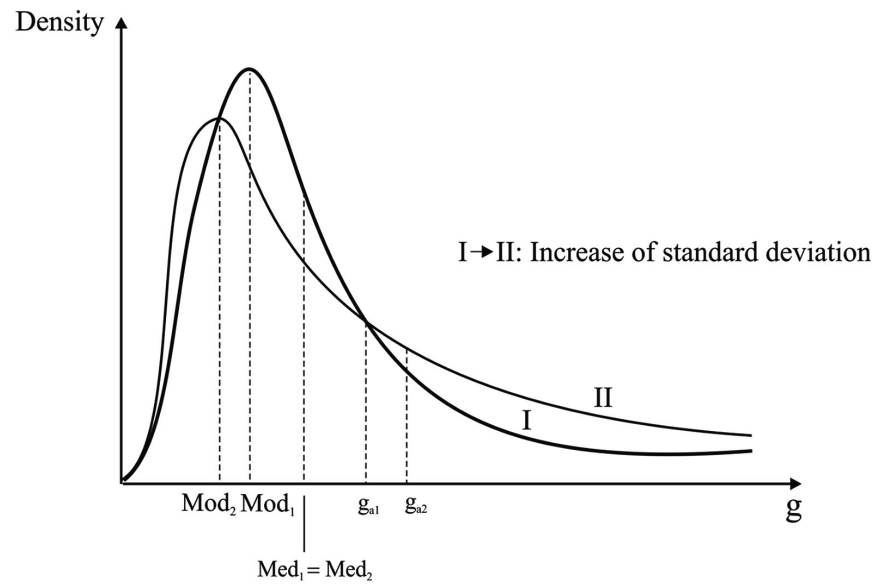

Figure 3. Left steep distribution of profits per unit of production. Source: Blümle (1989); own compilation.

Proposition 1: An increase in $\sigma$ will shift the arithmetic mean to the right.

Furthermore, we have:

$$
M O D=\exp \left(\mu-\sigma^{2}\right)
$$

Taking the full differential yields:

$$
\mathrm{d} M O D=(\mathrm{d} \mu-2 \sigma \mathrm{d} \sigma) \exp \left(\mu-\sigma^{2}\right)
$$

Proposition 2: An increase in $\sigma$ will shift the modus to the left.

Finally, we have:

$$
\begin{gathered}
M E D=\exp (\mu) \\
\mathrm{d} M E D=\exp (\mu)
\end{gathered}
$$

Proposition 3: An increase in $\sigma$ will not affect the median.

Besides, for any positive variance $\left(\sigma^{2}>0\right)$, the following order will hold: $M O D<M E D<g_{a}$.

And yet, the total sum of difference profits $(D P)$ in an economy (given the size of output $X$ ) equals to

$$
D P=g_{a} X
$$


Therefore, the volume of profits can only become large, ceteris paribus, as long as there exists a considerable dispersion of profits (i.e., greater differences in profits among the firms involved), given the size of the output. Hence, for the size of $D P$, each element of the product $g_{a} X$ is decisive. The distinct occurrence of technological progress is, most likely, responsible for a higher (or lower) dispersion of profits. The technological progress contributes to making the distribution of profits per unit of production more unequal. As a consequence, the arithmetic mean of these profits shifts to the right (see above) and marginal suppliers are crowded out.

In the following, we make use of the Gini coefficient $(G)$ instead of the variance/standard deviation $(\sigma)$, as both are interrelated via a monotone relationship (Guo \& Sell, 2019): More precisely, it holds that $\operatorname{Gini}=2 \Phi(\sigma / \sqrt{2})-1$ with $\Phi(x)$ being the standard normal distribution.

\section{An Intra-Firm Model of Innovation, Imitation and Personal Income Distribution}

\subsection{Stylized Facts and Assumptions}

We depart from the following stylized facts:

- technical progress (innovations) enhances the dispersion of profits: the distribution of profits becomes less equal;

- a higher variance of profits (see above) makes the arithmetic mean "walk" to the right.

- During this process, marginal suppliers are pushed out of the relevant market.

- The source of difference profits is clear: they stem from patents, a lack of market transparency and a temporary complicated access to the market. Profits are, at the same time, precondition and also incentive for risky investments. These investments, in turn, are necessary for the enforcement of technical progress.

- Profit differentials tend to increase the willingness to innovate. A high volume of profits is also important when it comes to finance innovations by one's own.

\subsection{The Growth Rate of Innovative Activity and the Dispersion of Personal Incomes}

- In other words: given a high dispersion of profits, and a variable income, the propensity to innovate should rise. We define:

- $I N p=$ propensity to innovate. The propensity to innovate $(I N p)$ and the propensity to imitate $(I M P)$-in analogy to the relationship between the marginal propensity to consume and the marginal propensity to save-must add to one:

- $I N p+I M p=1 ; \quad I M p=1-I N p$.

- For the growth rate of the propensity to imitate $\left(W_{I M p}\right)$, we assume the exis- 
tence of a negative, and, for reasons of simplicity, linear function, depending on the intra-firm Gini coefficient $(G)$ :

$$
\begin{gathered}
W_{I M p}=\frac{\mathrm{d} I M p / \mathrm{d} t}{I M p}=a_{1}-a_{2} G ; a_{1}, a_{2}>0 ; \quad W_{I N p}=1-W_{I M p} \\
W_{I N p}=1-W_{I M p}=1-\left(a_{1}-a_{2} G\right)=1-a_{1}+a_{2} G
\end{gathered}
$$

There exists a positive autonomous component $\left(a_{1}\right)$ explaining the growth rate of $I M p$ if $G=0$. Why? Without a spread/slope in the system of remuneration (wages, salaries, and profits), the mind of the employed workforce (including the management) pays less and less attention to innovation, as there is a complete lack of monetary incentives. Once a differentiation of work compensation starts to be implemented ( $G>0$ ), the growth rate in the propensity to imitate (innovate) has a worse (better) perspective. However, as in Okun's law, a substantial rise in the inequality of income distribution (growth rate) is in need to overcompensate the lack of inspiration among the workforce. This is, by the way, the effect of an unconditional basic income.

- Whenever the concentration of personal incomes is zero $(G=0)$, the growth rate of the propensity to innovate (imitate) will decline (increase):

$$
G=0 \Rightarrow w_{I M p}=a_{1}
$$

In this scenario, equity of incomes $(G=0)$ induces a severe decline in the propensity to innovate. The firm dedicates itself increasingly to imitation. Only a substantial differentiation/spread of wages, salaries, and management compensation induces a good and rising average productivity level and hence sufficient within-firm innovations:

$$
\begin{aligned}
& W_{I M p}>0 \text { only if } a_{1}-a_{2} G<0 ; a_{1}<a_{2} G \\
& W_{\text {INp }}>0 \text { only if } 1-a_{1}+a_{2} G>0 ; a_{2} G>a_{1}-1
\end{aligned}
$$

- If the growth rate of the propensity to imitate (and hence to innovate) is zero, we achieve a stationary state of personal income distribution within the firm:

$$
W_{I M p}=0 \Rightarrow G^{*}=\frac{a_{1}}{a_{2}}, W_{I N p}=0 \Rightarrow G^{*}=\frac{a_{1}-1}{a_{2}}=\frac{a_{3}}{a_{2}} \text {, for } a_{1}-1=a_{3} .
$$

From which, for consistency reasons, it necessarily follows: $a_{1}>1$. In the following Figure 4, we visualize the established relationship between the dispersion of personal incomes and the growth rate of the propensity to innovate.

\subsection{The Growth Rate of the Gini Coefficient and Innovative Activity}

- A high level of the propensity to innovate (imitate) will generate higher (lower) profits and thereby increase (decrease) the degree of within-firm income inequality, as measured by the growth rate of the Gini coefficient. However, there exits always a positive autonomous component $\left(b_{1}\right)$ responsible for a floor level growth rate in the differentiation of wages and salaries which unions cannot avoid, facing the forces of globalization and labor-saving technical progress: 


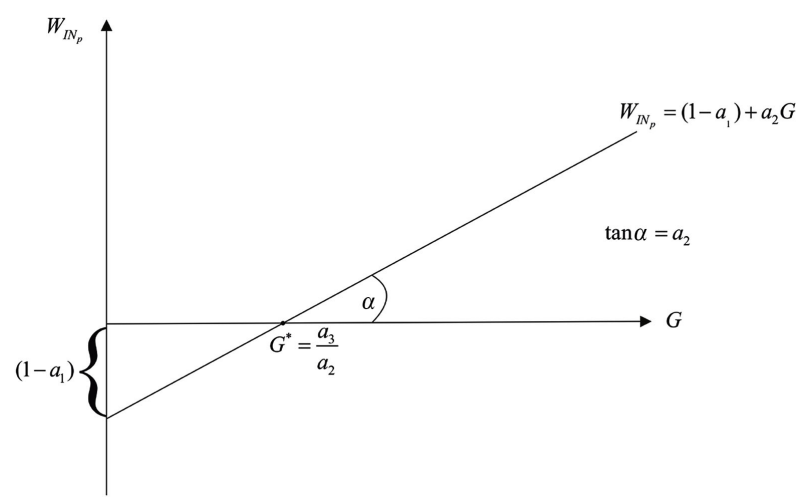

Figure 4. Growth rate of the propensity to innovate and dispersion of personal incomes. Source: own compilation.

$$
w_{G}=\frac{\mathrm{d} G / \mathrm{d} t}{G}=b_{1}-b_{2} I M p ; \quad w_{G}=b_{1}-b_{2}(1-I N p)=+\left(b_{1}-b_{2}\right)+b_{2} I N p .
$$

We assume $b_{1}-b_{2}<0$; hence: $b_{2}>b_{1}$. We define: $b_{2}-b_{1}=b_{3}$ which yields:

$$
w_{G}=\frac{\mathrm{d} G / \mathrm{d} t}{G}=-b_{3}+b_{2} I N p .
$$

- Whenever the propensity to imitate (innovate) turns zero, the growth rate of the Gini coefficient will become:

$$
I M p=0 \Rightarrow w_{G}=b_{1} ; \quad I N p=0 \Rightarrow w_{G}=-b_{3} ;
$$

- A stationary state is achieved, once the growth rate of the Gini coefficient becomes zero:

$$
w_{G}=0 \Rightarrow I M p^{*}=\frac{b_{1}}{b_{2}} ; \quad w_{G}=0 \Rightarrow I N p^{*}=\frac{b_{2}-b_{1}}{b_{2}}=\frac{b_{3}}{b_{2}}
$$

In the following Figure 5, we visualize the established relationship between the propensity to innovate and the growth rate of income dispersion.

Result:

$$
\begin{aligned}
& w_{I M p}=0 \Rightarrow G^{*}=\frac{a_{1}}{a_{2}} \text { and } w_{G}=0 \Rightarrow I M p^{*}=\frac{b_{1}}{b_{2}} \\
& w_{I N p}=0 \Rightarrow G^{*}=\frac{a_{3}}{a_{2}} \text { and } w_{G}=0 \Rightarrow I N p^{*}=\frac{b_{3}}{b_{2}}
\end{aligned}
$$

- The next question is not trivial: what is the relationship between the propensity to innovate (imitate), on the one hand, and the degree of concentration of intra-firm personal incomes, on the other hand: what determines $\mathrm{d} I N p / \mathrm{d} G$ ?

\subsection{The Propensity to Innovate and the Dispersion of Personal Incomes}

- For the growth rate of the propensity to innovate, we have:

$$
w_{l N p}=\frac{\mathrm{d} I N p / \mathrm{d} t}{I N p}=-a_{3}+a_{2} G \Leftrightarrow \frac{\mathrm{d} I N p}{\mathrm{~d} t}=\left(-a_{3}+a_{2} G\right) I N p
$$




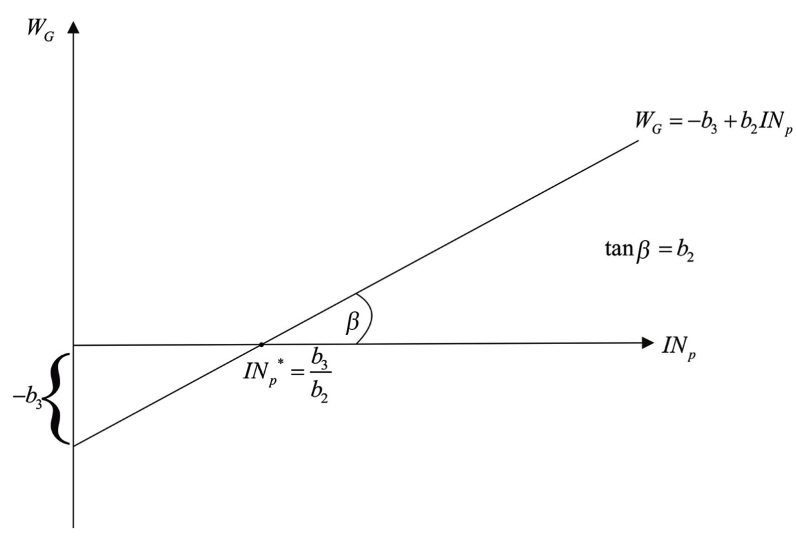

Figure 5. Growth of income dispersion and the propensity to innovate. Source: own compilation.

- Mutatis mutandis, the following holds for the growth rate of the dispersion of personal incomes:

$$
w_{G}=\frac{\mathrm{d} G / \mathrm{d} t}{G}=-b_{3}+b_{2} I N p \Leftrightarrow \frac{\mathrm{d} G}{\mathrm{~d} t}=\left(-b_{3}+b_{2} I N p\right) G
$$

- Building a quotient between $\mathrm{d} I N p / \mathrm{d} t$ and $\mathrm{d} G / \mathrm{d} t$ gives:

$$
\frac{\mathrm{d} I N p / \mathrm{d} t}{\mathrm{~d} G / \mathrm{d} t}=\frac{\mathrm{d} I N p}{\mathrm{~d} G}=\frac{\left(-a_{3}+a_{2} G\right) I N p}{\left(-b_{3}+b_{2} I Q\right) G}
$$

We can solve this equation using the so-called Lotka-Volterra-technique:

$$
\begin{gathered}
\left(\frac{-b_{3}}{I N p}+b_{2}\right) \mathrm{d} I N p=\left(\frac{-a_{3}}{G}+a_{2}\right) \mathrm{d} G \\
\int\left(\frac{-b_{3}}{I N p}+b_{2}\right) \mathrm{d} I N p=\int\left(-a_{3} / G+a_{2}\right) \mathrm{d} G \\
-b_{3} \ln I N p+b_{2} I N p=-a_{3} \ln G+a_{2} G+c \\
\exp \left(-b_{3} \ln I N p+b_{2} I N p\right)=\exp \left(-a_{3} \ln G+a_{2} G+c\right) \\
I N p^{-b_{3}} \mathrm{e}^{b_{2} I N p}=G^{-a_{3}} \mathrm{e}^{a_{2} G} \mathrm{e}^{c} ; \text { as: } I N p^{-b_{3}}=\mathrm{e}^{-b_{3} \ln I N p}
\end{gathered}
$$

We now proceed to derivate the maximum values, that is the points of vertical respective horizontal tangents. To achieve the points of horizontal tangents, we take the derivative of the left side of the above equation. For reasons of simplification, we define:

$$
I N p^{-b_{3}} \mathrm{e}^{b_{2} I N p}=G^{-a_{3}} \mathrm{e}^{a_{2} G} \mathrm{e}^{c} ; \text { as } I N p^{-b_{3}}=\mathrm{e}^{-b_{3} \ln I N p} ; \text { let: } I N p=x
$$

Then, we have:

$$
-b_{3} x^{-b_{3}-1} \mathrm{e}^{b_{2} x}+b_{2} x^{-b_{3}} \mathrm{e}^{b_{2} x}=0
$$

or

$$
x^{-b_{3}} \mathrm{e}^{b_{2} x}\left(-b_{3} x^{-1}+b_{2}\right)=0
$$

Besides the trivial solution of $x=0$, the further solution is obviously:

$$
x^{*}=b_{3} / b_{2}=I N p^{*}
$$


From the right side of the above equation we may achieve the points of vertical tangents by taking derivatives:

$$
G^{-a_{3}}\left(\mathrm{e}^{a_{2} G}\right) \mathrm{e}^{c}=\mathrm{e}^{c}\left(-a_{3} G^{-a_{3}-1} \mathrm{e}^{a_{2} G}+a_{2} \mathrm{e}^{a_{2} G} G^{-a_{3}}\right)=0
$$

or

$$
\mathrm{e}^{c} G^{-a_{3}} \mathrm{e}^{a_{2} G}\left(-a_{3} G^{-1}+a_{2}\right)=0
$$

Besides the trivial solution of $G=0$, the further solution is obviously:

$$
G^{*}=a_{3} / a_{2}
$$

- The solution may be depicted as a closed loop around the stationary equilibrium, $P^{*}$ (Figure 6):

$$
w_{I N p}=0 \Rightarrow G^{*}=\frac{a_{3}}{a_{2}} \text { and } w_{G}=0 \Rightarrow I N p^{*}=\frac{b_{3}}{b_{2}}
$$

Explaining the rationale of the stationary equilibrium $P^{*}$ :

- Gini coefficient $G^{*}=a_{3} / a_{2}$ : the higher $a_{2}$ is, the more will a stronger spread in the system of wages and salaries promote an increase in the propensity to innovate. The higher $a_{3}$ is, the sooner will a drop in the propensity to innovate occur, whenever there is a lack of concentration among personal incomes within the firm.

- Propensity to innovate $I N p^{*}=b_{3} / b_{2}$ : the smaller $b_{2}$ is, the less will we experience a further spread in the system of wages and salaries caused by a high propensity to innovate. Je larger $b_{3}$ is, the sooner will a lack of innovative activities result in a decline of the concentration of personal incomes.

Example:

Point D: minimum of the propensity to innovate $\rightarrow$ an increase is feasible with a greater dispersion of personal incomes: Point A: Here we have a maximum in the concentration of incomes (somehow a certain degree of overshooting vis-a-vis to the equilibrium level), more of the propensity to innovate is achievable only with less concentration of incomes. Hence, the maximum of the propensity to innovate is finally reached (Point B) along with a consolidation in the dispersion of incomes. However: Further reductions in the concentration of incomes stimulate imitations to the detriment of innovations (Point $\mathrm{C}$ ). Imitations dominate even at a now again increasing dispersion of personal incomes (this is a sort of ratchet effect). Finally, innovative (imitative) activity reaches a minimum (maximum) at Point D ...

\section{The Macroeconomic Cycle}

In Figure 7, we have reproduced the closed-loop developed theoretically above. We can now test, whether we can transfer the insights gained from the dynamics of innovation, imitation and personal income distribution at the firm level to the macroeconomic field of the business cycle. If so, we would contribute to reconcile the alleged disparity between microeconomics/market economics on the one hand and macroeconomics/business cycle economics on the other hand. 


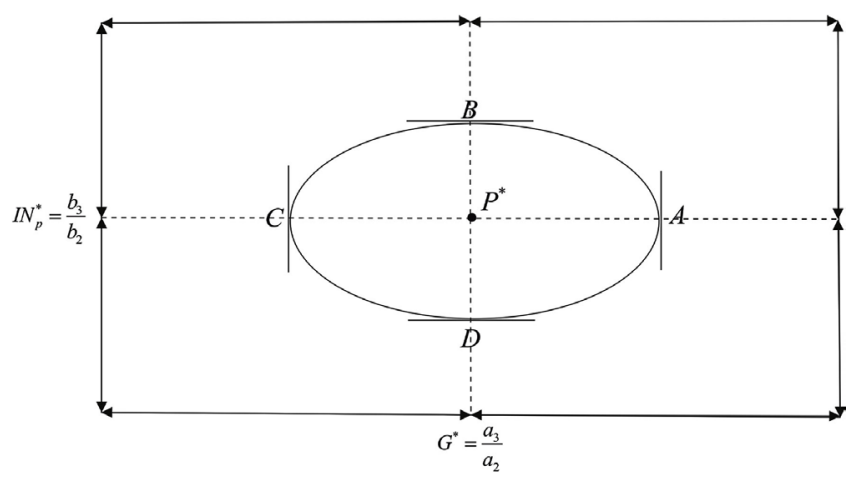

Figure 6. The cycle of income distribution and the propensity to innovate. Source: own compilation.

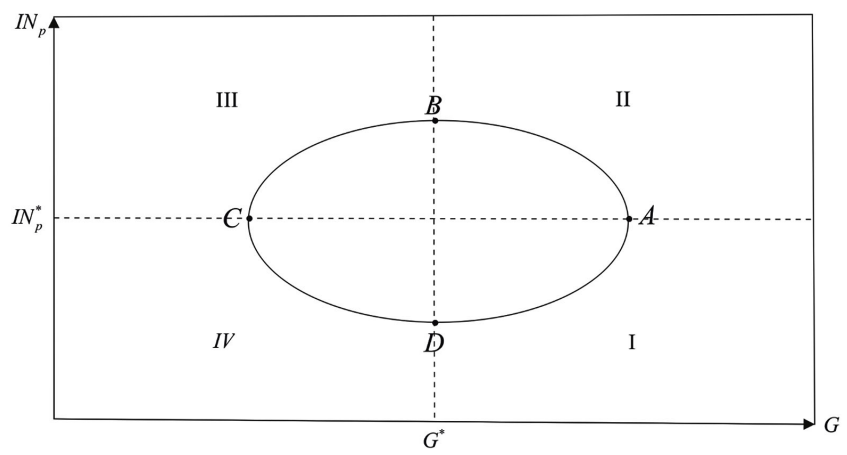

Figure 7. A stylized version of the business cycle. Source: own compilation.

\section{1) Economic Upswing}

Obviously, Point $\mathrm{D}$ is associated with an equilibrium in personal income distribution which is (when we move upwards and to the right) now destroyed (by the way, very much in the sense of Schumpeter) by innovations/technical progress, a rise in profits per unit of production (Barone curve!) due to the activities of pioneer entrepreneurs. The concentration of personal income rises while the wage quota necessarily drops.

2) Boom

From Point A on, innovations and related investments increase, new capacities are created. The profile of profits, however, begins to decline, so that concentration of personal incomes subsides. Employment and production go up, the GDP reaches a peak. However, productivity progress begins to slow down, costs will now increase, at least about prices.

3) Downswing

From Point B on, a decline of economic activity (at least relative) begins, accompanied by rising wages and salaries (the famous lag of tariff negotiations during the cycle becomes effective), dropping profits, the wage quota rises, the concentration of personal incomes comes down (and reaches a minimum at Point C). Innovation declines whereas imitation experiences a continuous (and at least relative) rise. Output and employment suffer a severe crunch.

4) Recession 
From Point $\mathrm{C}$ on, innovative activities decline further (below their stationary or average value), the share of imitations (innovations) finally reaches a peak (low) in point D. Firms organize a reduction of (idle) capacities. Production and employment are still falling. Unions agree to tolerate and give in to wage moderation (to curb dismissals of the employees) a policy, which tends to elevate once more the concentration of personal incomes.

\section{An Empirical Evaluation}

The above Figure 7 demonstrates the cyclical behavior of income distribution and innovation. The described pattern is taken to be a stylized fact of the business cycle. It also implies the existence of a sort of equilibrium value (steady-state) for income distribution and the propensity to innovate, respectively. The data for the following empirical analysis stem from the OECD 2019 (Gini coefficients ex-post) and Globalinnovationindex.org 2019 (Innovation index). The analysis is therefore necessarily of a macroeconomic nature.

The relationship found in Figure 8 (see for the estimation technique Stock \& Watson, 2012), which is the empirical corollary to Figure 4 from above, is concave (this type of curvature fits best the data points) and not linear, as assumed in the model from above. This implies that empirically, an increasing innovation activity (as measured here by the innovation index) has, on average, a positive, but a declining influence on the skewness of income distribution (as measured here by the "Delta", of the Gini index) change, the more we move to the right. This matches the insights from Gossen's second law and it is not surprising at all.

The relationship found in Figure 9), which is the empirical corollary to Figure 5 from above, is essentially U-shaped. This implies that empirical facts are slightly more complex than the linear model above suggested. Economically, the $\mathrm{U}$-shaped estimation function means the following: On the one hand, it seems that (reading Figure 9 from left to right) at the beginning (i.e. at low levels of the Gini coefficient) a move towards more inequality at first hinders innovation. But as we look further to the right, we realize that the income skewness distribution (and so the Gini coefficient) has to go beyond a certain or critical level so that only from then on a further increasing Gini coefficient will exert a positive influence on the change of the innovation index.

\section{Conclusion}

In this paper, we have made, to the best of our knowledge, a first attempt to link directly the economic variables of personal income distribution and innovation activity. The relationship postulated here works on both sides, that is skewness of personal income distribution drives the dynamics of innovation and at the same time it is innovation activity which tends to have an impact on the distribution of personal incomes and to push, ceteris paribus, towards more inequality of incomes. The model is essentially firm-oriented, and based on market processes, but, as we have seen, it can be easily transferred to the macroeconomy and thereby contribute to explain the four stylized phases of the business cycle. 


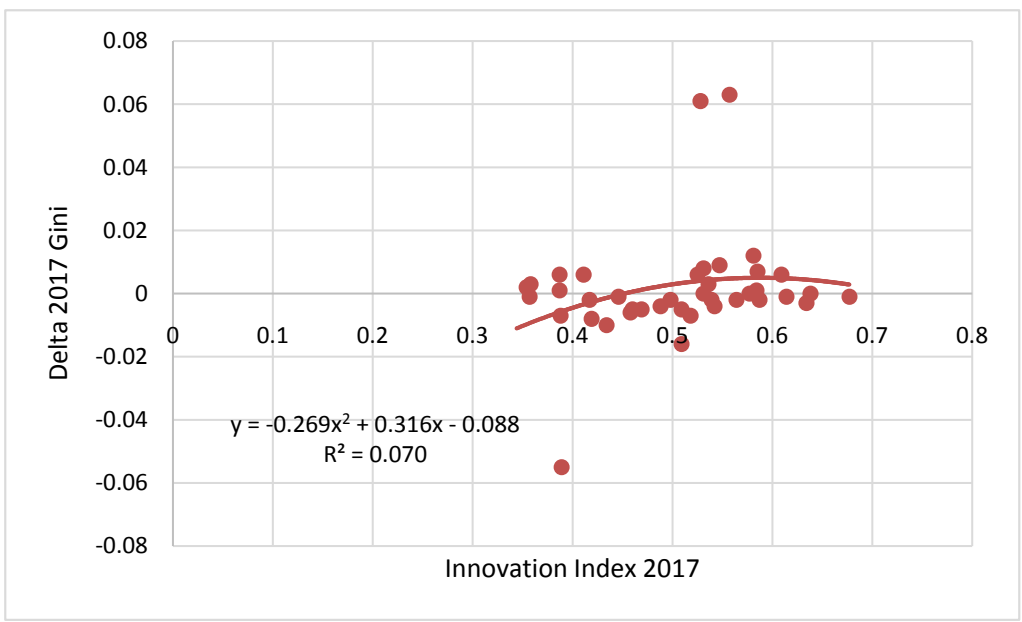

Figure 8. The impact of innovations on income distribution. Sources: OECD (2019), Globalinnovationindex.org (2019), own calculations.

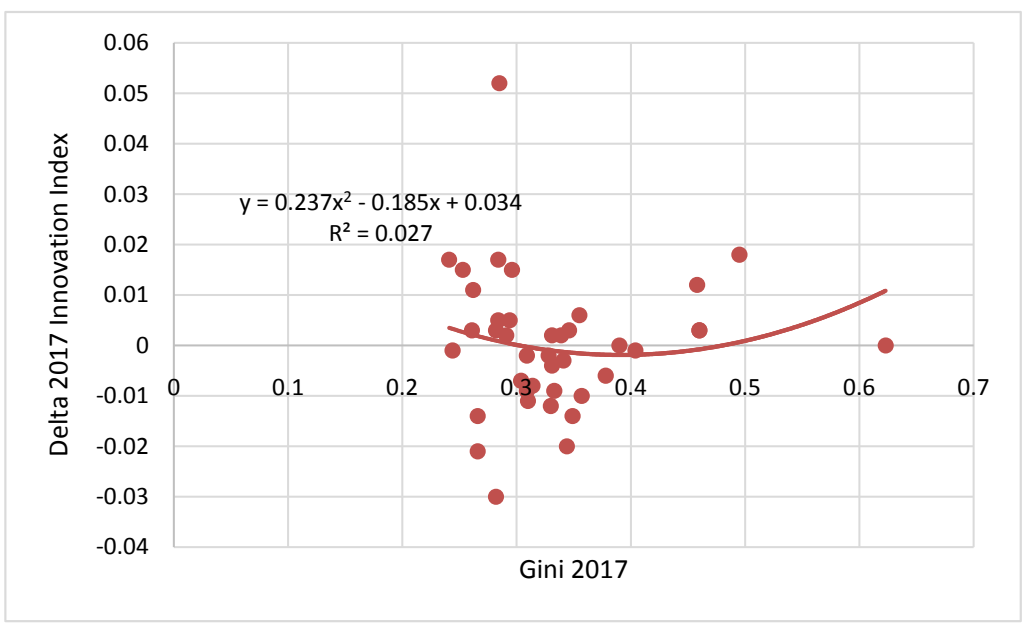

Figure 9. The impact of income distribution on innovation. Sources: OECD (2019), Globalinnovationindex.org (2019), own calculations.

The empirical check of the model is necessarily quite preliminary, given the lack of firm-specific data on innovation activities and personal income distribution within the firm. We, therefore, had to rely totally on macroeconomic data in our non-linear regression analysis. Here, the limitations are obvious, especially when it comes to using data of personal income distribution. The available Gini coefficients provided by the OECD are only ex-post figures. That means, that, on the one hand, we do not know how personal income distribution behaves before taxes and transfers, that is, ex-ante, under the impact of innovation activity. On the other hand, it would be ideal as well to know Gini coefficients ex-ante to assess their impact on innovation endeavors before the government corrects income distribution through taxes and transfers.

Nevertheless, our first empirical findings tend to modestly support and confirm the theoretical findings of this paper. As a consequence, we can add another 
point of view to the presumed conflict between economic growth (which primarily rests on technical progress, i.e. innovations), on the one side, and equity in the distribution of (personal) incomes, on the other.

\section{Conflicts of Interest}

The author declares no conflicts of interest regarding the publication of this paper.

\section{References}

Autor, D., Dorn, D., Katz, L. F., Patterson, C., \& Van Reenen, J. (2020). The Fall of the Labor Share and the Rise of Superstar Firms. Quarterly Journal of Economics, 135, 645-709. https://doi.org/10.1093/qje/qjaa004

Barone, E. (1935). Grundzüge der theoretischen Nationalökonomie (2nd ed.). Übersetzt und mit einem Anhang versehen von Hans Stähle. Mit einer Einführung von Joseph Schumpeter. Berlin: Dümmler Verlag.

Beichelt, F., \& Montgomery, D. (2003). Teubner-Taschenbuch der Stochastik. Berlin/Heidelberg/New York: Springer-Verlag.

https://doi.org/10.1007/978-3-322-80067-1

Blümle, G. (1989). Wachstum und Konjunktur bei Differenzgewinnen-Ein Schumpeter-Modell der wirtschaftlichen Entwicklung. In H. J. Ramser, \& H. Riese (Eds.), Beiträge zur angewandten Wirtschaftsforschung (pp. 13-37). Berlin: Springer. https://doi.org/10.1007/978-3-642-74285-9_2

Bradley, M. E., \& Mosca, M. (2012). Enrico Barone's "Ministry of Production": Content and Context. European Journal of the History of Economic Thought, 21, 664-698. https://doi.org/10.1080/09672567.2012.708768

Globalinnovationindex.org (2019). SCJohnson College of Business (Ed.), Global Innovation Index 2019.

Guo, Y., \& Sell, F. L. (2019). Equilibrium and Convergence in Personal Income Distribution? How European Countries Performed during a Phase of Huge Economic Turbulence (2004-2017). Neubiberg: Mimeo.

Helmstädter, E. (1986). Dynamischer Wettbewerb, Wachstum und Beschäftigung. In G. Bombach et al. (Eds.), Technologischer Wandel-Analyse und Fakten (pp. 67-82). Tübingen: J. C. B. Mohr.

Karabasz, I. (2020). Das Innovationsparadox. Handelsblatt (10) January 15, 2020, 23.

Külp, B. (2017). Funktionen und Dysfunktionen von Gewinnen. Elektronic Ressource, Website of Prof. Dr. Bernhard Külp, Freiburg i. Br.

OECD (2019). OECD Income Distribution Database (IDD): Gini, Poverty, Income, $\mathrm{Me}$ thods and Concepts. OECD.org.MyOECD.

Sell, F. L. (2020). Static and Dynamic Price Effects Motivated by Innovation and Imitation: Novel Insights Using the Barone's Curve. Contemporary Economics, 14, 73-89.

Stock, J. H., \& Watson, M. M. (2012). Introduction to Econometrics (3rd ed.). Boston, MA, Columbus, $\mathrm{OH}$ : Pearson International Edition. 